\title{
PENERAPAN METODE EXPONENTIAL MOVING AVERAGE PADA PERAMALAN PENGGUNAAN AIR DI PDAM KOTA GORONTALO
}

\author{
Wa Salmi ${ }^{1}$, Ismail Djakaria ${ }^{2}$, Resmawan $^{3}$ \\ ${ }^{12}$ Program Studi Statistika, Fakultas MIPA, Universitas Negeri Gorontalo \\ ${ }^{2}$ Program Studi Matematika, Fakultas MIPA, Universitas Negeri Gorontalo \\ ${ }^{3}$ Universitas Negeri Gorontalo \\ e-mail: salmhyaliasa@ gmail.com
}

Abstrak

Menghadapi musim kemarau, besar kemungkinan adanya kekurangan air ataupun kelebihan pendistribusian pada satu titik, saat pembagian ke setiap rumah yang menggunakan air PDAM dalam setiap harinya. Hal ini akan mengakibatkan ketidakstabilan masyarakat dalam menggunakan air dan kurang akuratnya penggunaan. Oleh karena itu, dilakukan peramalan jumlah penggunaan air di PDAM Kota Gorontalo untuk periode selanjutnya. Metode yang digunakan untuk melakukan peramalan yakni metode Exponential Moving Average. Kriteria dalam menentukan metode terbaik didasarkan pada nilai Mean Absolute Deviation dan Mean Absolute Percentage Error. Setelah peramalan setiap konstanta smoothing dibandingkan, model terbaik. dalam meramalkan jumlah penggunaan air di PDAM Kota Gorontalo adalah Exponential Moving Average dengan konstanta smoothing 0,15 karena memiliki nilai MAD dan MAPE yang terkecil.

Kata Kunci: Exponential Moving Average; Mean Absolute Deviation; MAPE

\begin{abstract}
Facing the dry season, it is probable that there is a lack of water or excess distribution at one point during distribution to every house that uses PDAM water every day. This will result in community instability in using water and inaccurate users. Therefore, forecasting of the amount of water used in PDAM Kota Gorontalo for the next period. The method used to forecast is the Exponential Moving Average method. Criteria in determining the best method is based on the value of Mean Absolute Deviation and Mean Absolute Percentage Error. After forecasting each smoothing constant is compared, the best model. in predicting the amount of water use in PDAM Kota Gorontalo is an Exponential Moving Average with a smoothing constant of 0.15 because it has the smallest MAD and MAPE values.

Keywords: Exponential Moving Average, Mean Absolute Deviation, MAPE
\end{abstract}

\section{PENDAHULUAN}

Perusahaan Daerah Air Minum (PDAM) adalah salah satu dari beberapa badan usaha milik daerah (BUMD), yang mengelola kebutuhan air minum pada saat ini PDAM memiliki peran sangat penting bagi masyarakat dalam hal mendukung kelancaran pembangunan daerah, sehinggga keberhasilan PDAM harus selalu diupayakan (Kurniawati 2009). Perusahaan Daerah merupakan salah satu penggerak ekonomi di suatu daerah, selain perusahaan milik daerah, terdapat perusahaan milik Negara dan perusahaan swasta. Tujuan pemerintah mendirikan perusahaan daerah yaitu untuk menjadi penyokong dalam pembangunan daerah. Air adalah unsur yang tidak dapat dipisahkan dari kehidupan manusia, bahkan dapat dipastikan tanpa pengembangan sumberdaya air secara konsisten peradaban manusia tidak akan mencapai tingkat yang dinikmati sampai saat ini. Oleh karena itu 
pengembangan dan pengelolahan sumber daya air merupakan dasar peradaban manusia (Putro et al. 2018). Program pengembangan dan pengelolaan sumber daya dapat didukung melalui perencanaan dengan melakukan peramalan data penggunaan air. Peramalan adalah seni dan ilmu untuk memperkirakan kejadian di masa depan. Hal ini dapat dilakukan dengan melibatkan pengambilan data histori dan memproyeksikan ke masa mendatang dengan suatu bentuk model matematis (Sucipto and Syaharuddin 2018). Peramalan menurut jangka waktu biasanya diklasifikasikan berdasarkan horizon waktu masa depan yang dilingkupinya antara lain jangka pendek, jangka menengah dan jangka panjang (Heizer, Jay. Render, Barry. Munson 2017). Data penggunaan air yang dikumpulkan setiap periode waktu merupakan jenis data time series. Data time series seringkali mengandung ketidakteraturan yang akan menyebabkan prediksi yang beragam. Untuk menghilangkan ketidakteraturan tersebut maka digunakan Simple Moving Average (SMA) dengan mengambil beberapa nilai yang sedang diamati, memberikan rataan dan menggunakannya untuk memprediksi nilai untuk periode waktu yang akan datang (Yaffee and McGee 2000).

Penentuan metode peramalan pada data time series perlu diketahui pola dari data tersebut sehingga peramalan menggunakan metode yang sesuai dengan pola data dapat dilakukan (Setiawan et al. 2019). Pola data dapat dibedakan menjadi empat jenis yakni pola horizontal, trend, musiman dan siklik (Makridakis et al. 1997). Bila pola data trend terjadi, data mengalami kenaikan atau penurunan sehingga tidak dapat menggunakan metode peramalan yang pada umumnya seperti SMA. Metode Exponential Moving Average (EMA) merupakan pengembangan SMA model rata-rata bergerak yang terboboti ke arah exponential. Pada model EMA, data terbaru terboboti lebih besar dari data yang telah lalu dan bobot terlama mendekati nol yang membentuk grafik secara exponential (Prapcoyo 2018). Penggunaan metode peramalan tergantung pada pola data yang akan dianalisis. Jika metode yang digunakan dianggap benar untuk melakukan peramalan, maka pemilihan metode peramalan terbaik didasarkan pada tingkat kesalahan prediksi (Sundari et al. 2019).

Adapun penelitian EMA yang menjadi relevansi dalam penelitian antara lain, (Widodo and Hansun 2016) menggunakan EMA untuk menentukan trend harga saham perusahaan. Kriteria model terbaik berdasarkan persentase trend harga saham. Selain itu penelitian lain yang memiliki relevansi adalah (Anggono 2019) yang menggunakan EMA untuk peramalan harga saham di Indonesia Stock Echange, dalam kasus ini pemilihan model terbaik didasarkan pada perhitungan resiko dan pengembalian.

Pada penelitian ini EMA akan digunakan untuk peramalan jumlah penggunaan air bersih di PDAM Kota Gorontalo. PDAM digunakan untuk keperluan sehari-hari. Untuk menghadapi musim kemarau, besar kemungkinan adanya kekurangan air ataupun kelebihan pendistribusian pada satu titik saat pembagian ke setiap rumah yang menggunakan air PDAM dalam setiap harinya. Hal ini akan mengakibatkan ketidakstabilan masyarakat dalam menggunakan air dan kurang akuratnya penggunaan air. Adapun yang dilakukan pada penelitian ini menggunakan EMA didasarkan pada ukuran kesalahan Mean Absolute Deviation (MAD) dan Mean Absolute Percentage Error (MAPE). Data yang digunakan berupa data rata-rata penggunaan air bersih di PDAM Kota Gorontalo dari Januari 2010 sampai dengan Desember 2019.

\section{METODE PENELITIAN}

Penelitian ini dilakukan selama 3 bulan dimulai pada November 2019 sampai dengan Januari 2020. Variable pada penelitian ini adalah penggunaan air di PDAM Kota Gorontalo 
dari Januari 2010 hingga Desember 2019 dan menggunakan metode Sampling Jenuh. Adapun data penelitian yang digunakan bersumber dari Kantor PDAM Kota Gorontalo. Metode peramalan yang digunakan adalah metode EMA. Sebelum melakukan peramalan EMA, dilakukan SMA terlebih dahulu untuk menentuka Orde SMA terbaik berdasarkan MAD dan MAPE.

\section{HASIL DAN PEMBAHASAN}

\subsection{Statistika Deskriptif}

Data yang digunakan adalah Jumlah Penggunaan Air di PDAM Kota Gorontalo periode Januari 2010 sampai Desember 2019 dan dideskripsikan pada Tabel 1.

Tabel 1: Deskriptif Data

\begin{tabular}{cccc}
\hline Mean & Minimum & Maksimum & Varians \\
\hline $522077,80 \mathrm{~m}^{3}$ & $405178 \mathrm{~m}^{3}$ & $693800 \mathrm{~m}^{3}$ & $62649330 \mathrm{~m}^{3}$
\end{tabular}

Berdasarkan Tabel 1, data penggunaan air di PDAM Kota Gorontalo periode Januari 2010 sampai Desember 2019 mempunyai nilai rata-rata sebesar $522077 \mathrm{~m}^{3}$, penggunaan air terbanyak terjadi pada bulan Juli pada tahun Januari 2016 sedangkan penggunaan air terendah terjadi pada bulan Maret 2011 dan varians sebesar $62649330 \mathrm{~m}^{3}$.

\subsection{Analisis Pola Data}

Untuk mengetahui pola data historis jumlah penggunaan air di PDAM Kota Gorontalo dapat menggunakan Microsoft Office Excel. Plot data historis jumlah penggunaan air di PDAM Kota Gorontalo dari Januari 2010 sampai Desember 2019 dapat dilihat pada Gambar 1.

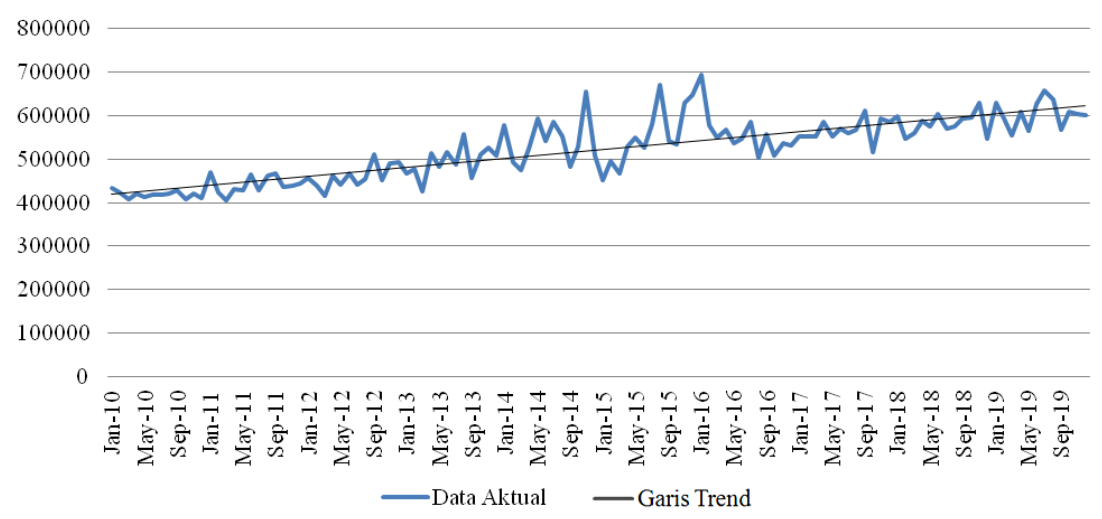

Gambar 1: Plot Data Jumlah Penggunaan Air Di PDAM Kota Gorontalo

Berdasarkan Gambar 1 dapat diketahui bahwa data memiliki unsur trend berupa trend naik, terlihat dari garis trend yang cenderung naik. Pada grafik tersebut juga terlihat 
rata-ratanya konstan serta varians yang homogen.Oleh karena data memiliki unsur trend maka dapat dilakukan peramalan menggunakan metode EMA.

\subsection{Penentuan Orde Simple Moving Average}

Sebelum melakukan peramalan menggunakan metode EMA maka harus dilakukan penentuan Orde SMA terlebih dahulu dengan melakukan SMA yang dilanjutkan dengan menghitung nilai ukuran kesalahan MAD dan MAPE. Nilai MAD dan MAPE dari masingmasing Orde SMA dapat dilihat pada Tabel 2.

Tabel 2: Orde SMA

\begin{tabular}{ccc}
\hline Orde SMA & Nilai MAD & Nilai MAPE \\
\hline SMA(2) & 31499,98 & $5,90 \%$ \\
\hline SMA(3) & 30635,08 & $5,69 \%$ \\
\hline SMA(4) & 30480,73 & $5,65 \%$ \\
\hline SMA(5) & 29330,99 & $5,42 \%$ \\
\hline SMA(6) & 29430,22 & $5,44 \%$ \\
\hline SMA(7) & $\mathbf{2 9 3 1 4 , 8 0}$ & $\mathbf{5 , 4 0 \%}$ \\
\hline SMA(8) & 29879,85 & $5,48 \%$ \\
\hline SMA(9) & 30230,42 & $5,55 \%$ \\
\hline SMA(10) & 30750,95 & $5,63 \%$ \\
\hline SMA(11) & 31417,13 & $5,74 \%$ \\
\hline SMA(12) & 31186,17 & $5,68 \%$ \\
\hline
\end{tabular}

Berdasarkan Tabel 2 dapat diketahui Orde SMA yang memiliki nilai MAD dan nilai MAPE terkecil yakni masing-masing sebesar 29314,80 dan 5,40\% adalah SMA(7). Orde SMA(7) akan digunakan untuk meramalkan jumlah penggunaan air di PDAM Kota Gorontalo menggunakan metode EMA. Adapun Model SMA(7) adalah:

$$
\operatorname{SMA}(7)=\frac{\text { Data }_{1}+\text { Data }_{2}+\text { Data }_{3}+\text { Data }_{4}+\text { Data }_{5}+\text { Data }_{6}+\text { Data }_{7}}{7}
$$

\subsection{Peramalan Metode Exponential Moving Average}

Setelah melakukan peramalan SMA didapatkan bahwa orde terbaik adalah SMA(7). Konstanta smoothing EMA yakni $0<\alpha<1$ yakni $\alpha=(0,01)$ hingga $\alpha=(0,99)$. Selanjutnya dilakukan peramalan EMA untuk setiap konstanta telah ditentukan dan dilanjutkan dengan menghitung nilai ukuran kesalahan peramalan MAD dan MAPE dapat dilihat pada Tabel 3. 
Tabel 3: Konstanta Smoothing EMA

\begin{tabular}{|c|c|c|c|c|c|c|c|}
\hline No & $\begin{array}{l}\text { Konstanta } \\
\text { Smoothing }\end{array}$ & MAD & MAPE & No & $\begin{array}{l}\text { Konstanta } \\
\text { Smoothing } \\
\end{array}$ & MAD & MAPE \\
\hline 1 & 0,01 & 75460,19 & 13,40 & 51 & 0,51 & 31424,28 & 5,86 \\
\hline 2 & 0,02 & 56424,74 & 10,04 & 52 & 0,52 & 31515,19 & 5,87 \\
\hline 3 & 0,03 & 45631,86 & 8,15 & 53 & 0,53 & 31607,55 & 5,89 \\
\hline 4 & 0,04 & 39256,62 & 7,03 & 54 & 0,54 & 31700,01 & 5,91 \\
\hline 5 & 0,05 & 35734,81 & 6,42 & 55 & 0,55 & 31798,59 & 5,93 \\
\hline 6 & 0,06 & 33527,83 & 6,05 & 56 & 0,56 & 31910,01 & 5,95 \\
\hline 7 & 0,07 & 32161,43 & 5,82 & 57 & 0,57 & 32027,42 & 5,98 \\
\hline 8 & 0,08 & 31134,74 & 5,64 & 58 & 0,58 & 32144,54 & 6,00 \\
\hline 9 & 0,09 & 30384,54 & 5,52 & 59 & 0,59 & 32261,37 & 6,03 \\
\hline 10 & 0,10 & 29919,24 & 5,44 & 60 & 0,60 & 32377,94 & 6,05 \\
\hline 11 & 0,11 & 29569,84 & 5,38 & 61 & 0,61 & 32499,11 & 6,07 \\
\hline 12 & 0,12 & 29409,80 & 5,36 & 62 & 0,62 & 32626,81 & 6,10 \\
\hline 13 & 0,13 & 29312,78 & 5,35 & 63 & 0,63 & 32754,16 & 6,13 \\
\hline 14 & 0,14 & 29235,82 & 5,35 & 64 & 0,64 & 32881.14 & 6,15 \\
\hline 15 & 0,15 & 29159,54 & 5,34 & 65 & 0,65 & 33007,76 & 6,18 \\
\hline 16 & 0,16 & 29167,55 & 5,34 & 66 & 0,66 & 33134,01 & 6,20 \\
\hline 17 & 0,17 & 29162,57 & 5,35 & 67 & 0,67 & 33259,89 & 6,23 \\
\hline 18 & 0,18 & 29188,11 & 5,36 & 68 & 0,68 & 33389,8 & 6,25 \\
\hline 19 & 0,19 & 29218,59 & 5,37 & 69 & 0,69 & 33529,37 & 6.28 \\
\hline 20 & 0,20 & 29247,46 & 5,38 & 70 & 0,70 & 33672,09 & 6.31 \\
\hline 21 & 0,21 & 29281,54 & 5,39 & 71 & 0,71 & 33817,15 & 6,34 \\
\hline 22 & 0,22 & 29322,18 & 5,40 & 72 & 0,72 & 33962,04 & 6,36 \\
\hline 23 & 0,23 & 29361,98 & 5,41 & 73 & 0,73 & 34107,66 & 6,39 \\
\hline 24 & 0,24 & 29408,89 & 5,42 & 74 & 0,74 & 3425,47 & 6,42 \\
\hline 25 & 0,25 & 29457,83 & 5,43 & 75 & 0,75 & 34396,46 & 6,45 \\
\hline 26 & 0,26 & 29509,8 & 5,45 & 76 & 0,76 & 34545,53 & 6,48 \\
\hline 27 & 0,27 & 29559,65 & 5,46 & 77 & 0,77 & 34695,6 & 6,51 \\
\hline 28 & 0,28 & 29614,94 & 5,47 & 78 & 0,78 & 34844,91 & 6,54 \\
\hline 29 & 0,29 & 29671,79 & 5,49 & 79 & 0,79 & 34993,44 & 6,57 \\
\hline 30 & 0,30 & 29724,91 & 5,50 & 80 & 0,80 & 35141,21 & 6,55 \\
\hline 31 & 0,31 & 29789,37 & 5,51 & 81 & 0,81 & 35288,16 & 6,62 \\
\hline 32 & 0,32 & 29855,25 & 5,53 & 82 & 0,82 & 35434,32 & 6,65 \\
\hline 33 & 0,33 & 29924,21 & 5,54 & 83 & 0,83 & 35579,67 & 6,68 \\
\hline 34 & 0,34 & 29992,72 & 5,56 & 84 & 0,84 & 35743,36 & 6,71 \\
\hline
\end{tabular}




\begin{tabular}{llllllll}
\hline 35 & 0,35 & 30071,22 & 5,57 & 85 & 0,85 & 35872,38 & 6,74 \\
\hline 36 & 0,36 & 30147,14 & 5,59 & 86 & 0,86 & 36020,09 & 6,77 \\
\hline 37 & 0,37 & 30220,59 & 5,61 & 87 & 0,87 & 36171,89 & 6,80 \\
\hline 38 & 0,38 & 30293,39 & 5,62 & 88 & 0,88 & 36330,82 & 6,83 \\
\hline 39 & 0,39 & 30370,63 & 5,64 & 89 & 0,89 & 34891,37 & 6,86 \\
\hline 40 & 0,40 & 30456,74 & 5,66 & 90 & 0,90 & 36647,53 & 6,89 \\
\hline 41 & 0,41 & 30545,42 & 5,67 & 91 & 0,91 & 36805,27 & 6,92 \\
\hline 42 & 0,42 & 30632,69 & 5,69 & 92 & 0,92 & 36963,84 & 6,95 \\
\hline 43 & 0,43 & 30718,66 & 5,71 & 93 & 0,93 & 371280,33 & 6,98 \\
\hline 44 & 0,44 & 30806,72 & 5,73 & 94 & 0,94 & 37293,89 & 7,01 \\
\hline 45 & 0,45 & 30894,06 & 5,75 & 95 & 0,95 & 374912,22 & 7,04 \\
\hline 46 & 0,46 & 30980,03 & 5,76 & 96 & 0,96 & 37624,44 & 7,08 \\
\hline 47 & 0,47 & 31064,72 & 5,78 & 97 & 0,97 & 37788,51 & 7,11 \\
\hline 48 & 0,48 & 31151,87 & 5,80 & 98 & 0,98 & 37954,95 & 7,14 \\
\hline 49 & 0,49 & 31243,09 & 5,82 & 99 & 0,99 & 38127,27 & 7,17 \\
\hline 50 & 0,50 & 31333,42 & 5,84 & & & & \\
\hline
\end{tabular}

Berdasarkan Tabel 3 dapat dilihat nilai hasil perhitungan ukuran kesalahan MAD dan MAPE dari konstanta smoothing EMA. Konstanta smoothing yang memiliki nilai MAD dan MAPE terkecil adalah konstanta smoothing 0,15 yakni MAD sebesar 29159,54 dan MAPE sebesar 5,34\%. 
Untuk $t=1$

Adapun model peramalan EMA yang didapat yakni:

Untuk $t>1$

$$
\begin{aligned}
& E M A_{1}=Y_{1} \\
& E M A_{1}=421682
\end{aligned}
$$

$$
\begin{aligned}
& E M A_{t+1}=\alpha Y_{t}+(1-\alpha) \times S_{t} \\
& E M A_{t+1}=0,15 Y_{t}+(1-0,15) \times S_{t} \\
& E M A_{t+1}=0,15 Y_{t}+0,85 S_{t}
\end{aligned}
$$

Setelah didapatkan model peramalan EMA, maka dilakukan peramalan EMA dan dibandingkan dengan data aktual seperti pada Gambar 2.

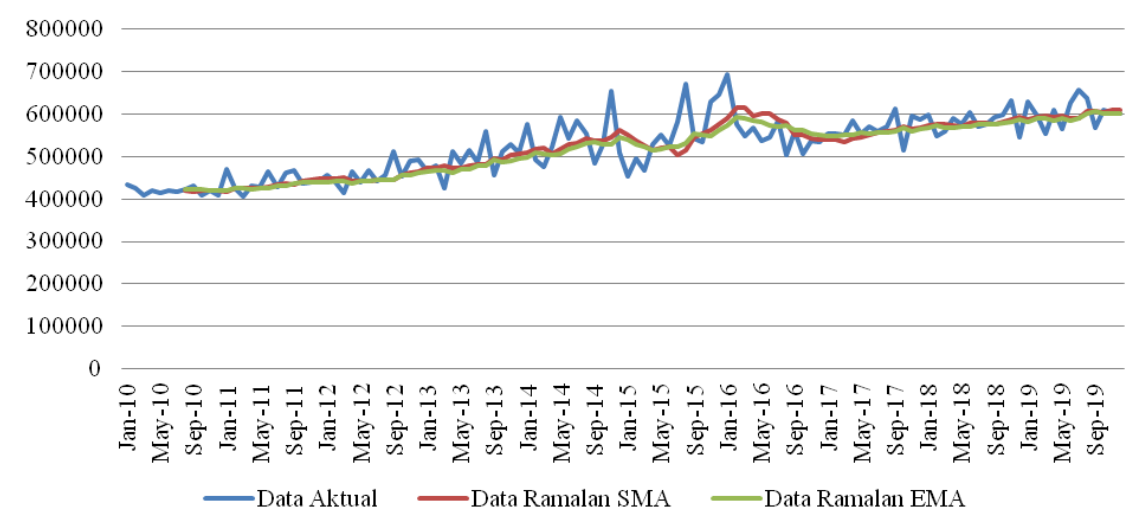

Gambar 2: Grafik Data Aktual, Data Ramalan SMA dan Data Ramalan EMA

Gambar 2 menunjukkan garik perbandingan nilai data aktual, nilai peramalan SMA(7) dengan nilai dari hasil peramalan menggunakan metode EMA menggunakan konstanta smoothing terbaik yakni 0,15. Terlihat bahwa grafik peramalan SMA dan EMA mengikuti pola dan mendekati nilai pada data aktual. Namun, metode EMA lebih baik untuk digunakan dalam meramalkan jumlah penggunaan air di PDAM Kota Gorontalo.

\subsection{Peramalan Periode Selanjutnya}

Hasil peramalan jumlah penggunaan air di PDAM Kota Gorontalo menggunakan metode EMA dengan konstanta smoothing 0,15 dapat dilihat pada Tabel 4 .

Tabel 4: Hasil Peramalan

\begin{tabular}{cc}
\hline Waktu (Tahun 2020) & Hasil Peramalan $\left(\boldsymbol{m}^{\mathbf{3}}\right)$ \\
\hline Januari & 601905,28 \\
\hline Februari & 602285,76 \\
\hline Maret & 602609,17 \\
\hline April & 602884,07 \\
\hline
\end{tabular}




\begin{tabular}{cc}
\hline Mei & 603117,73 \\
\hline Juni & 603316,35 \\
\hline Juli & 603485,17 \\
\hline Agustus & 603628,67 \\
\hline September & 603750,65 \\
\hline Oktober & 603854,32 \\
\hline November & 603942,45 \\
\hline Desember & 604017,36 \\
\hline
\end{tabular}

Tabel 4 menunjukkan bahwa jumlah penggunaan air di PDAM Kota Gorontalo tertinggi adalah pada bulan Desember $2020604017,36 \mathrm{~m}^{3}$ sebesar sedangkan penggunaan terendah sebesar $601905,28 \mathrm{~m}^{3}$ pada Januari 2020. Terlihat peramalan jumlah penggunaan air bertambah setiap bulan atau mengalami pola trend naik.

\section{KESIMPULAN}

Model Exponential Moving Average terbaik dalam meramalkan jumlah penggunaan air di PDAM Kota Gorontalo adalah model EMA dengan menggunakan konstanta smoothing 0,15 yang memiliki MAD sebesar 29159,54 dan MAPE sebesar 5,34\%. Hasil peramalan menunjukkan bahwa jumlah penggunaan air di PDAM Kota Gorontalo diperkirakan tertinggi pada bulan Desember 2020 sebesar $604017,36 \mathrm{~m}^{3}$ sedangkan penggunaan terendah sebesar 601905,28 $\mathrm{m}^{3}$ terjadi pada bulan Januari 2020.

\section{DAFTAR PUSTAKA}

Anggono, A. H. (2019), "Investment Strategy Based on Exponential Moving Average and Count Back Line," 8, 153-161.

Heizer, Jay. Render, Barry. Munson, C. (2017), Operations management: sustainability and supply chain management, Journal of purchasing and supply management.

Kurniawati, E. (2009), “Analisis Rasio Keuangan untuk Menilai Kinerja Perusahaan Daerah Air Minum," Buletin Pascasarjana Universitas Hasanuddin, 6, 112-122.

Makridakis, S. G., Wheelwright, S. C., and Hyndman, R. J. (1997), Forecasting: Methods and Applications, Wiley.

Prapcoyo, H. (2018), "PERAMALAN JUMLAH MAHASISWA MENGGUNAKAN MOVING AVERAGE,” Telematika, 15, 67.

https://doi.org/10.31315/telematika.v15i1.3069.

Putro, B., Furqon, M. T., and Wijoyo, S. H. (2018), "Prediksi Jumlah Kebutuhan Pemakaian Air Menggunakan Metode Exponential Smoothing (Studi Kasus : PDAM 
Kota Malang)," Jurnal Pengembangan Teknologi Informasi dan Ilmu Komputer, 2 , 4679-4686.

Setiawan, D. A., Wahyuningsih, S., and Goejantoro, R. (2019), "Peramalan Produksi Kelapa Sawit Menggunakan Winter's dan Pegel's Exponential Smoothing dengan Pemantauan Tracking Signal," Jambura Journal of Mathematics, 2, 1-14. https://doi.org/10.34312/jjom.v2i1.2320.

Sucipto, L., and Syaharuddin, S. (2018), "Konstruksi Forecasting System Multi-Model untuk pemodelan matematika pada peramalan Indeks Pembangunan Manusia Provinsi Nusa Tenggara Barat," Register: Jurnal Ilmiah Teknologi Sistem Informasi, 4, 114. https://doi.org/10.26594/register.v4i2.1263.

Sundari, S. S., Susanto, W., and Revianti (2019), "Sistem Peramalan Persediaan Barang Dengan Weight Moving Average Di Toko The Kids 24," in Konferensi Nasional Sistem \& Informatika 2015, STMIK STIKOM.

Widodo, D., and Hansun, S. (2016), "Implementasi Simple Moving Average dan Exponential Moving Average dalam Menentukan Tren Harga Saham Perusahaan," Jurnal ULTIMATICS, 7, 113-124. https://doi.org/10.31937/ti.v7i2.354.

Yaffee, R. A., and McGee, M. (2000), An Introduction to Time Series Analysis and Forecasting: With Applications of SAS® and SPSS®, Academic Press. 